\title{
Yukiyo Kasai (guest editor). "Dynamics, Stability \& Tradition: the Role of the Religions of Iranian Speakers in Central and Eastern Asia"
}

Christelle Jullien

\author{
(2) OpenEdition \\ Journals \\ Édition électronique \\ URL : https://journals.openedition.org/abstractairanica/54112 \\ DOI : 10.4000/abstractairanica. 54112 \\ ISSN : 1961-960X \\ Éditeur : \\ CNRS (UMR 7528 Mondes iraniens et indiens), Éditions de l'IFRI
}

Référence électronique

Christelle Jullien, « Yukiyo Kasai (guest editor). "Dynamics, Stability \& Tradition: the Role of the Religions of Iranian Speakers in Central and Eastern Asia" », Abstracta Iranica [En ligne], Volume 42-43 | 2021, document 20, mis en ligne le 30 décembre 2021, consulté le 18 décembre 2022. URL : http:// journals.openedition.org/abstractairanica/54112; DOI : https://doi.org/10.4000/abstractairanica. 54112

Ce document a été généré automatiquement le 18 décembre 2022.

Tous droits réservés 


\title{
Yukiyo Kasai (guest editor).
}

"Dynamics, Stability \& Tradition: the Role of the Religions of Iranian Speakers in Central and Eastern

\author{
Asia"
}

Christelle Jullien

\section{RÉFÉRENCE}

Yukiyo Kasai (guest editor). "Dynamics, Stability \& Tradition: the Role of the Religions of Iranian Speakers in Central and Eastern Asia", Entangled Religions 11/6 (2020), ISSN 2363-6696 (Online).

1 Ce volume thématique est dédié à la question de l'implication des communautés religieuses de langue iranienne dans la stabilité et le maintien des traditions, mais aussi dans leurs évolutions, en Asie centrale et orientale. Parmi les 4 contributions, mentionnons plus spécialement :

2 Max Deeg, "The "Brilliant Teaching": Iranian Christians in Tang China and Their Identity" (p.1-29). Cette contribution s'intéresse au processus de conversion des Chinois et pose la question d'une religion chrétienne prosélyte versus une religion propre à une diaspora venue d'Iran. L'A. s'interroge sur l'identité culturelle et religieuse de cette communauté expatriée de langue syriaque, chrétiens d'origine perse, sogdienne ou bactrienne.

3 Erica C. D. Hunter, “Turfan : Connecting with Seleucia-Ctesiphon" (p.1-36). L'A. souligne de nouveau l'importance de l'héritage spirituel et théologique des chrétiens syroorientaux parmi les communautés de langue iranienne à Turfan, et montre l'importance des relations maintenues avec Séleucie-Ctésiphon parallèlement aux 
efforts déployés pour l'évangélisation in situ - ce dont témoignent les nombreux lectionnaires bilingues et la variété de langues dans lesquelles ils ont été rédigés. À l'appui d'un texte liturgique de Turfan, le plus complet conservé (MIK III 45) et daté entre 771 et 884 de notre ère, elle évalue le rôle de la liturgie comme outil de mémoire communautaire en faveur de ces liens avec la capitale sassanide, à travers deux exemples : celui de Barșauma évêque de Nisibe, et celui de Širarān, que la tradition donne comme sœur du roi Šābuhr II et évangélisatrice de la région de Merw (dans une version sensiblement différente de celle restituée par l'Histoire syro-orientale de Séert puisqu'elle apparaît comme une missionnaire de premier plan).

\section{AUTEURS}

CHRISTELLE JULLIEN

CNRS, CeRMI, Paris 